\title{
THE PERSISTEXCE OF ACTION OF THE DIGITALINS *
}

\author{
ROBERT A. HATCHER \\ NEW YORK
}

An attempt has been made in the present research to determine approximately the length of time during which the action of several of the digitalins persists after the introduction of suitable doses directly into the circulation. with the hope of throwing some light on their so-called cumulative action.

One finds many references in the literature to this so-called cumulative action of the digitalins, but there have been few investigations of the phenomena other than clinical.

The term cumulation is used somwhat loosely, but it is generally understood to mean the action which is manifested rather sudidenly after the continued use of doses which singly do not aluse jerceptible effects.

Van der Heide states that Mégeraud was the first to study this subject by means of animal experimentation in $38 \% 9$, but the rescarch was incomplete, so far as cumulation was concerned, since that investigator was interested mainly in the histologic changes induced in certain organs during chronic digitalis poisoning.

Schmiedeberg" states that the three digitalis principles, digitalein, digitalin and digitoxin, are absorber with relative difficulty and slowly excreted, and on these factors the so-called cumulative action of digitalis is dependent in part: in part on a storage of the active substance in the organism when digitalis is used for prolonged periods during renal disturbance.

These deductions of Schmiedeberg's appear to be based on theoretical considerations; at least, I am not aware of any experiments on which they are bascd directly, and certain of the digitalins appear to be excreted through the gastro-intestinal tract to a greater extent than through the kidneys."

* Read in the Section on Pharmacology and Therapeutics of the American Medical Association, at the Sixty-Third Annual Session, held at Atlantic City, June, 1912.

* From the Laboratory of l'harmacology, Cornell Lniversity Medical College, New York.

*The expenses of this investigation were borne in part by the Therapeutic Research Fund of the American Vedical Association.

1. Van der Heide: Areh. f. exper. Path. u. Pharm., 1885. xix, 127.

2. Schmiedeberg: Arch. f. exper. Path. u. Pharm., 1883, xvi, 185.

3. Hateher: Am. Jour. Plysiol., 1909, xxiii, 303. 
Van der Heide ${ }^{1}$ investigated the cumulative action of helleborein after injecting it subcutaneously into rabbits, and that of digitalin and helleborein administered to dogs by the mouth and rectum, and subcutaneously.

Owing to his employment of these several modes of administration, and of varying amounts of the drugs at irregular intervals, and even of both drugs in the same experiment, in some instances, it is difficult to form a correct opinion of the value of the conclusions at which van der Heide arrived. His results are complicated still further by the fact that he used an impure digitalin, which consisted of digitalein mainly, and this was dissolved in a 3 per cent. infusion of digitalis for subcutaneous injection; hence his results are due to the use of digitalis rather than to true digitalin, in those experiments where helleborein was not employed.

Van der Heide calls attention to the fact that the word cumulation indicates that the phenomena were attributed to a storage of the active principles in the organism, but he remarks that the earlier writers had no very clear conception of the method by which storage took place, and I might add that the same degree of uncertainty still exists.

$\mathrm{He}$ concluded that the dog and rabbit showed cumulative symptoms so far as the cardiac effects were concerned, and habituation on the part of the nervous system.

The next important pharmacological investigation of this cumulative action of the digitalins was made by Fraenke, ${ }^{4}$ who administered several of the digitalins to cats by subcutaneous injection and attempted to observe the cumulation by means of the slowing of the pulse-rate, by the onset of gastro-intestinal symptoms, and by the death of the animal, following the repeated injection of doses which were individually too small to produce these effects.

Fraenkel's conclusions have been quoted rery frequently, but I believe that he made important errors, and, since certain of his statements are irreconcilable with mine, it will be necessary to discuss some of his experiments later in connection with my own.

Cloetta $^{5}$ tried to estimate the storage of one of the digitalins in the hearts of frogs and rats which had been poisoned with large amounts of the drug, but he was unable to detect even traces of the poison in that organ.

Schliomensun found that a group of substances (alcoholic phosphatids) could be isolated from the hearts taken from the human cadaver and from the dog, and that these substances appeared to possess an especial capacity for combining with the digitalins chemically, while the

4. Fraenkel: Arch. f. exper. Path. u. Pharm., 1903, li, 84.

5. Cloetta and Fischer: Arch. f. exper. Path. u. Pharm., 1906, liv, 294.

6. Schliomensun: Arch. f. exper. Path. u. Pharm., 1910, lxiii, 294. 
corresponding fractions obtained from the livers and skeletal muscles had no such affinity.

This observation of Schliomensun's would seem to indicate the possibility of storage of the digitalins in the heart.

Straub ${ }^{7}$ concluded that no storage of ouabain occurred in the tissues of the heart, as a result of his perfusion experiments, in which he found that the poison could be washed from the heart before it stopped beating by merely substituting fresh Ringer's solution for the poisoned perfusion fluid.

Lhoták von Lhota ${ }^{8}$ studied chronic digitalis poisoning induced in rabbits by oral and subcutaneous administration, and concluded that rabbits showed cumulative effects up to the tenth day of the poisoning, and tolerance thereafter.

The use of the rabbit for this type of experiment, and the employment of the digitalins by oral and subcutaneous administration for these investigations will be discussed in connection with my own results with such experiments.

\section{CAUSES OF ACCUMULATION, SO-CALLED}

Absorption and excretion play an important rôle in the so-called cumulative actions of the digitalins, but it is an extraordinary fact that we know almost nothing about either of these processes, except that the rate of absorption of these bodies from the alimentary tract is variable.

One finds extremely loose statements in the literature concerning the length of time during which the digitalins remain in the blood-stream after their introduction jnto the circulation, but so far as I have been able to learn these statements are not supported by experimental evidence, and the crude attempts made by van der Heide to detect the digitalins in the organs and the circulating blood are hardly worthy of mention; but the matter assumes much importance in view of the statement made by Straub, ${ }^{7}$ that the standstill of the perfused frog's ventricle depends on the concentration of the poison in the perfusing fluid and not on the total amount which passes through the heart, and that during perfusion no storage (in the common acceptation of the word) takes place in the tissues of the frog's heart.

It may be stated here that experiments still in progress in our laboratory show that practically all of a fatal dose of ouabain leaves the bloodstream within about three minutes after its injection into the reins of a cat, and we have also found that the cat's heart is poisoned prompt]y when ouabain is injected in extremely dilute solutions (1-250,000) at such a rate that its dilution in the blood-stream must be less than one in five hundred millions if it leaves the circulation as rapidly under these

7. Straub: Biochem. Ztschr., 1911, xxx, 392.

8. von Lhota, L.: Arch. int. de pharm. et de therap., 1910, xx, 451. 
conditions as it does when it is injected more rapidly, and if such is the case there can be little doubt that the action of ouabain on the intact mammalian heart depends on the total amount which passes through the heart, and not on the concentration in which it exists in the blood, for the concentration just mentioned is vastly less than that which Straub found necessary to bring the perfused frog's heart to a standstill.

The slowing of the pulse-rate and the cardiac irregularity, which maj be induced in many animals by the continued use of suitable doses of the digitalins have been utilized by several observers for the study of the onset and duration of the digitalis action, but it is true, nevertheless, that the effects of digitalis on the heart-rate in the cat are quite variable and many of my myographic tracings, taken at various intervals of time following the intravenous administration of large doses of the digitalins, give no visible evidence of their action on the heart, and in many cases these tracings are in no way different from those taken from normal animals; but it is impossible to suppose that the digitalins so administered have produced no action whatever, though the effects of such action are not perceptible in the tracings.

Even in those animals in which digitalis causes slowing of the pulse rate, that effect is induced only after the administration of fairly large doses. If, for the sake of illustration, we accept 25 per cent. of the fatal dose as the minimum amount which will be required in a given case to slow the heart-rate appreciably, it follows that this effect will persist only until elimination has reduced the amount in operation to a point where it becomes ineffective, at which time even a small dose will suffice to raise the amount in operation to the effective point and slowing will be induced again; for the smallest dose which produces measurable symptoms must consist of fractions which singly are insufficient to produce measurable effects.

This latent digitalis action often escapes attention in man and it may then become the basis for the so-called cumulative action, because of the small additional amount of the drug which then suffices to raise the action to the level where toxic symptoms are manifested.

This is understood readily when one remembers that the full therapeutic effect of digitalis is separated from the toxic action only by an imaginary line.

Briefly, then, one may investigate the so-called cumulative action of the digitalins by studying their absorption and excretion; by determining the length of time during which these principles remain in the bloodstream after they have entered the circulation; he may study the question of their storage in the tissues, particularly in the heart and nervous system; he may attempt to determine the duration of action by observing the objective symptoms, such as the slowing of the pulse-rate and the 
cardiac irregularity, which they induce, as Fraenkel did; or, he may estimate directly the degree to which the previously administered drug is still effective, and the length of time during which the action persists.

As a matter of fact, while casting about for the best means of investigating the subject I have experimented along nearly all the lines just mentioned, but the methods which I have employed are quite different from those used previously, and the results of these investigations will be published in a series of papers.

In the research with which this paper deals I have attempted to estimate the latent action of the digitalins as well as that which induces symptoms which are readily observed; in other words, I have tried to determine the length of time during which the action of a single large dose, or repeated doses, of these bodies persists, and the relative intensity of the persisting action after a given interval of time.

\section{TECHNIC}

The following method was used in estimating the persistence of action of the digitalins in the cat and dog in the larger number of experiments which I have to report:

The fatal dose of the digitalis body for a given species was determined in a series of experiments in which the drug was injected slowly and continuously from a buret into the veins of the animals until death resulted after the typical symptoms of digitalis poisoning

Having thus determined the fatal dose of a digitalin, a toxic, but not fatal, dose of the drug in measured amount was injected from a hypodermic syringe into the veins of a normal animal, which was then kept under observation for the required period of time, varying from one to thirty days. The animal was then placed on the operating board and the amount of the drug which was then required to cause death was determined in the way just described for a normal animal.

The difference between the fatal dose for the test animal which had previously received the initial dose and that required by a normal animal of the same weight must be due to the persisting action of the initial dose.

The following, taken from the protocol of an experiment, will serve to illustrate this method of estimating the persistence of action of digitalis :

May 16, 1912: Cat, female, weight $2.55 \mathrm{~kg}$.; $11: 31$ a. m., heart-rate 248 per minute; $11: 31 \frac{1}{2}$, heart-rate 207 per minute; $2: 45$ p. m., heart-rate 210 ; cat much excited; $2: 55$, injected $80 \mathrm{mg}$. digitalis per $\mathrm{kg}$. by vein; $4: 05$, emesis.

May 17: 10:32 a. m., animal depressed; heart-rate 258-252.

May 18: 10:05 a. m., appears nearly normal; heart-rate 210.

May 20: 1:25 p. m., appears quite normal; heart-rate 256.

May 24: 10:00 a. m., anesthetized; digitalis injected slowly by vein; 10:48, toxic symptoms; injection stopped; 10:52, animal died; $62 \mathrm{mg}$. digitalis per $\mathrm{kg}$. of body-weight had been injected.

A normal cat requires a dose of $100 \mathrm{mg}$. of digitalis per $\mathrm{kg}$. of bodyweight to cause death, but the test animal in the experiment just cited required only $62 \mathrm{mg}$. per $\mathrm{kg}$. - a difference of $38 \mathrm{mg}$. per $\mathrm{kg}$. - which represents the persistence of action of the initial dose after an interval of eight days. 
I have used ouabain (the so-called crystalline strophanthin of Thoms) for estimating this latent action of the digitalis principles in nearly all of the experiments recorded in Tables 1 to 5 , inclusire, and Table $\gamma$ and 10 , becanse of the greater accuracy which is permitted by its use. When ouabain was not used the fact is so stated in the footnotes accompanying the tables.

The use of ouabain in this way is based on the results obtained by Hatcher and Brody, who found that ouabain and the various digitalins were capable of replacing each other in the estimation of the fatal dose; for example, if 50 per cent. of the fatal dose of digitoxin and 50 per cent. of the fatal dose of ouabain were injected into the veins of a cat the effect was the same as that which followed the injection of a fatal dose of either ouabain or digitoxin alone, except for the fact that when ouabain was used with digitoxin in this way death resulted more promptly than when digitoxin was used alone, because of the comparative slowness with which just fatal doses of digitoxin act, whereas ouabain acts promptly when just fatal doses are administered, and, curiously, the combination of fractional doses of digitalis or digitoxin with ouabain also acts promptly.

This permits of greater accuracy in the estimation of the fatal dose of digitalis or digitoxin than would be possible were either of those bodies used alone in the manner previously described.

The employment of ouabain also permits of a more accurate determination of the latent action of digitoxin, digitalis and other digitalins, than wonld be possible by means of those digitalins themselves for the final test; and furthermore, the insolubility of certain of these principles, such as digitoxin and digitalin, interferes with their slow and continuous intravenous administration.

The following protocol (in brief) of an experiment illustrates this method of estimating the latent action of a digitalin:

April 16, 1912: Cat. gray striped, female, weight $2.2 \mathrm{~kg} . \quad 3: 35$ p. m., $0.4 \mathrm{mg}$. digitoxin per $\mathrm{kg}$. in 3.2 c.c. 6 per cent. alcohol, by vein; $4: 15$, emesis; $4: 25$, convulsion; $4: 50$, symptoms suggest that dose is fatal.

April 17: $3: 15 \mathrm{p}$. m., attempts to vomit; death seems imminent.

April 20:9:30 a. m., weight $1.9 \mathrm{~kg}$; heart is very rapid; $11: 22$ ouabain in $1-100,000$ solution, by vein; $11: 49$, deat 1 after $0.026 \mathrm{mg}$. ouabain per $\mathrm{kg}$., or 26 per cent. of the average fatal dose.

Since the animal received 26 per cent. of the average fatal dose of oubain four days after the initial dose of digitoxin, it follows that r $_{4}$ per cent. of the fatal dose was attributable to the persistence of action of the digitoxin.

When the interval between the first dose and the final test is only a few hours or a day the sum of the amounts injected is almost the same

9. Hatcher and Brody: Am. Jour. Pharm., 1910, Ixxxii, 360. 
as that which would be required at a single injection to cause deatl. because the effects of a fairly large dose of digitalis or digitoxin persist almost unchanged for a day.

When the interval following the administration of a given initial dos is as much as a week, the amount required to cause death at the time of the final test is somewhat variable because elimination takes place at rerr. different rates in different animals; but even as late as a month after the intrarenous injection of a nearly fatal dose of digitalis the test anjmal may require less than a normal animal would to cause death, showing that the action of digitalis sometimes persists even after such a long interial during which there has been no drug administered.

\section{MATURE OF PERSISTING ACTION}

It will suggest itself at once that this difference between the amount required to kill the normal, and that required to kill the test, animal after such a long interval of time is to be attributed to injury which the heart has sustained from the initial action of the digitalis rather than to any digitalis still operating on the heart.

Against such an argument is the fact that the cat's lieart may be poisoned to an equal degree with ouabain, and after an interval of twentyfour to forty-eight hours following a nearly fatal dose the animal behares like a nearly normal one, requiring almost as large a dose to cause death as a normal animal of the same weight would require.

The rabbit may be given a very nearly fatal dose of digitalis or dicitoxin (the action of which is extremely persistent in the cat), but after two or three hours, the heart has so far recovered its normal condition that it will require a full fatal dose to cause death.

One might suppose this rapid elimination of digitoxin and digitalis by the rabbit to be due to luabituation, but it follows the first dose.

It is difficult to account for the great differences in the persistence of action of the several digitalins in the same animal, or in that of the same digitalin in different animals, except on the bypothesis that the digitalins are eliminated at very different rates.

I have determined the fatal dose and the persistence of action of a number of the digitalins for the cat in the manner described, and have attempted to carry out similar experiments on other animals, including the dog, rabbit and guinea-pig, with some of the more important members of the digitalis group, but this was not feasible and a different procedure har to be adopted with the rabbit, while the attempt to use the guinea-pis for the experiments was abandoned. 
The white rat shows nervous symptoms following the injection of large doses of digitoxin, and these symptoms appear to overshadow the cardiac action. The phenomena have not been investigated by us, but it was observed that slight stimuli, such as are induced by a sudden noise, or touching the cage, were followed by violent strychmin-like reflexes, and clonic conrulsions which gradually subsided. Later the convulsions were absent, but a slight stimulus gave rise to violent trembling. These symptoms are present in a mild degree in the rabbit after large doses of digitoxin.

The action of digitoxin is more persistent than that of other principles of this group, and since its action persists for only a few days in the dog it seemed to be hardly worth while to test the more rapidly eliminated digitalins on that animal.

I believe that the cat behaves more like man toward the digitalins than does any other animal which is available for these experiments; hence the cat has been used in much the larger number of my experiments.

The results obtained in these experiments on cats and dogs are given in Tables 1 to $\gamma$; the experiments on rabbits will be considered later.

In these tables the initial dose, the dose required to cause the death of the animal after the interval of time following the initial dose, and the persistence of action are all expressed in percentages of the average fatal dose for the normal animal.

As previously stated, the figure which expresses the persistence of action is gotten by subtracting the figure representing the dose required after the interval following the initial dose, from 100 per cent. Thus the first animal of the first series of Table 1 required 83 per cent. of the average fatal dose for a normal animal to cause death after an interval of one day after the initial dose; hence the persistence of action in that case was equal to 17 per cent. of the average fatal dose for a normal animal of that size.

The arrangement used in the tables is intended to facilitate the study of the results obtained, for it would be necessary for the reader to consider such doses as $0.1 \mathrm{mg}$., $5 \% 5 \mathrm{mg}$. and $70 \mathrm{mg}$., if actual doses were given expressed in $\mathrm{mg}$. per $\mathrm{kg}$. of weight.

The fatal intravenous dose of each of the digitalins used for each of the species of animals employed in this research may be found in Table 11. These doses are expressed in $\mathrm{mg}$. of the drugs per $\mathrm{kg}$. of body weight of the animal, and from these doses may be calculated the dose used in any experiment, should anyone care to do so.

Ouabain was used in freshly prepared solution in the final test of the persistence of action, as previously stated, in most of the experiments and where it was not used the fact is stated in a footnote. 
Tabie 1.-Persistence of Digitalis Actiox in Cats

Experi-
ment
$\cdots \cdots$
$\cdots$

$1-B \ldots \ldots \ldots$

$2-3 \ldots \ldots \ldots$

$3-B \ldots \ldots \ldots \ldots$

4-B $\ldots \ldots \ldots$

$5-B \ldots \ldots \ldots$

6-B $\ldots \ldots \ldots \ldots$

$7 \cdot B \ldots \ldots \ldots$

$8-B \quad \ldots \ldots \ldots$

$9-B \ldots \ldots \ldots$

10-B
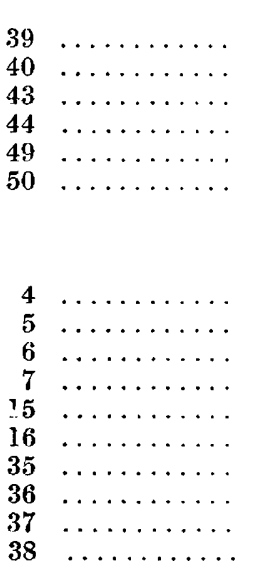

Initial
Dose
Per Cent.
of Fatal

Dose Required After Interval

Persistence Interval of Action in Per Cent. Days of Fatal

\section{SERIES 1}

50
50
50
50
50
50
$16.5 \times 2$
$16.5 \times 2$
$16.5 \times 2$
40

$\begin{array}{rr}83 & 17 \\ 56 & 44 \\ 50 & 50 \\ 54 & 46 \\ 110 & -10 \\ 75 & 25 \\ 81 & 19 \\ 77 & 23 \\ 79 & 21 \\ 92 & 8\end{array}$

SERIES 2

$\begin{array}{rrrr}96 & 115 & -15 & 28 \\ 108 & 74 & 26 & 29 \\ 100 & 32 & 68 & 11 \\ 100 & 42 & 58 & 11 \\ 100 & 52 & 48 & 10 \\ 100 & 77 & 23 & 9\end{array}$

SERIES 3

$\begin{array}{rrrr}45 & 62 & 38 & 33 \\ 45 & 45 & 55 & 34 \\ 40 & 117 & -17 & 33 \\ 40 & 76 & 24 & 33 \\ 45 & 64^{*} & 36 & 9 \\ 45 & 76^{*} & 24 & 9 \\ 60 & 122 & -22 & 14 \\ 84 & 73 & 27 & 12 \\ 60 & 84 & 16 & 28 \\ 60 & 88 & 12 & 28\end{array}$

SERIES 4

$\begin{array}{llr}1-S & \ldots \ldots \ldots \ldots & 75 \\ 2-S & \ldots \ldots \ldots & 75 \\ 3-5 & \ldots \ldots \ldots & 75 \\ 4-S & \ldots \ldots \ldots & 75 \\ 5-S & \ldots \ldots \ldots & 75 \\ 6-S & 75 \ldots \ldots & 75 \\ 7-S & \ldots \ldots \ldots & 75 \\ \text { 8-S } & \ldots \ldots \ldots \ldots & 75\end{array}$

*Digitalis used for final test.

$\begin{array}{lrr}51 & 49 & 30 \\ 77 & 23 & 30 \\ 81 & 19 & 21 \\ 68 & 39 & 21 \\ 67 & 33 & 10 \\ 91 & 99 & 5 \\ 67 & 33 & 5 \\ 38 & 69 & 5\end{array}$

\section{DISCUSSION OF TABLE I.}

The scheme of tabulation used here was not intended at the time the experiments were made, hence the numbers assigned to the experiments are not in sequence. Some of the animals died during the interval following the initial dose, as in series 2 , in which six of the twelve died. The initial dose in these twelve experiments was intended to be as nearly fatal as possible without actually killing the animals. 
The animals used in experiments $\mathrm{r}-\mathrm{B}$ to $9-\mathrm{B}$ received two initial doses, each being 16.5 per cent. of the fatal, on two successive days, and in those experiments the intervals are reckoned from the dates of the first doses.

Some animals required more than 100 per cent. of the average fatal dose after the specified interval of time, such animals being tolerant, while in some other cases the amount required to cause death is quite as far below the amount which we would expect as those just cited are above it. Such individual differences are always seen in biological testings, but Experiments 4 and 5 of the third series require individual consideration. In both of these cases the animals were either very susceptible, or there was some error in technic.

Aside from the examples just mentioned there are great irregularities to be observed in the doses required to cause death after the intervals of time following the initial doses, and this is to be expected in view of the fact that there are two interacting causes of these irregularities.

Since these figures will receive the closest scrutiny and possibly the severest criticism, it will be worth while to discuss them here briefly.

In Experiment 1-S of the fourth series the animal required only 51 per cent. of the average fatal dose after an interval of thirty days following an initial dose reckoned at 75 per cent. of the fatal, and in 6-S of the same serics 91 per cent. of the average fatal dose was required to cause death after an interval of only five days following an initial dose of the same amount as that received by the animal previously mentioned.

Such discrepancies appear at first glance to render the results almost useless, but a simple calculation will suffice to show that a comparatively slight difference in susceptibility on the part of one animal, and of tolerance on the part of the other, will explain even these great variations from the average.

If we suppose that the first of these two animals was susceptible to such a degree that it would require 20 per cent. less than the average fatal dose to cause death (and it could not have been much more susceptible, because it survived 75 per cent. of the average fatal), we shall have the following equation for this experiment:

Fatal dose, $80 \mathrm{mg}$. per $\mathrm{k}$.: initial dose $(75 \div 80=) 94$ per cent. of the fatal; dose required after interval $(51 \div 80 \Rightarrow 64$ per cent. of fatal, leaving persistence of action equal to 36 per cent. of fatal.

This would not be far from what we might expect in case the elimination was slower than normal in this animal. In the same way we may explain the unusually slight degree of persistence of action in the case of the other animal. If we suppose that this animal was tolerant to such a degree that it would require 20 per cent. more than the average fatal dose to cause death, we would then hare the following equation: 
Fatal dose, $120 \mathrm{mg}$. per $\mathrm{kg}$. of body-weight; initial dose $(75 \div 120=) 62.5$ per cent. of fatal; dose required after interval $(91 \div 120 \Rightarrow 76$ per cent. of fatal, leaving persistence of action equal to 24 per cent. of fatal.

This would be far nearer the amount which we should expect than that shown in the table.

It was found after completion of the experiments that intervals of three weeks and more were too long except when they followed the very largest initial doses, because they prolong the average of the duration of action unduly when they follow doses smaller than those which the animal. just survives.

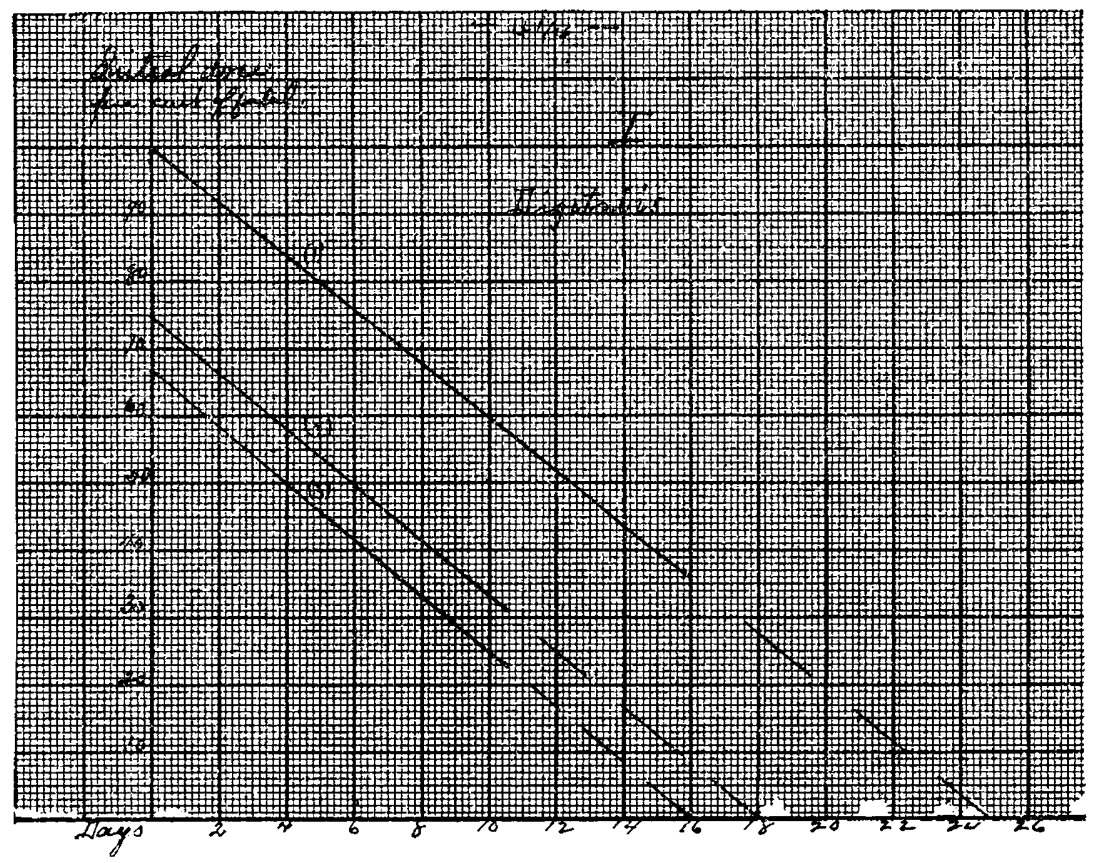

Diagram 1.- Showing persistence of action of digitalis. Upper line based on experiments in Series 2 of Table 1; middle line based on six experiments in Series 4, Table 1; lower line based on all experiments in Series 2, and all others in Table 1, except those in which interval is four weeks or more.

Reference to the several tables will show that the cat, dog and rabbit, manifest the persistence of action of digitoxin in the order of their susceptibility, as illustrated in Diagram 6, and I have gained the impression that individuals of the same species exhibit a similar relationship between these factors, the more tolerant individuals seeming to show less persistence of action after similar intervals than the more susceptible after doses which are relatively equal so far as one can judge by objective symptoms. (See discussion of Table 6.) 
The averages of the results of the experiments given in several of the tables are shown diagrammatically. In these diagrams the unbroken lines indicatc the decline of the action between the initial doses and the time of the final tests, and they are then continued as broken lines. While it is very probable that the elimination should be represented more accurately by curves, I have no data for the construction of such curves.

Eight of the ten experiments in the first series of Table 1 give the following averages: The initial dose was 45 per cent. of the fatal; the interval was about four days, and the persistence of action was equal to about 27 per cent. of the fatal. The entire series gives an interval of nine days, with persistence of action equal to 25 per cent. of the fatal, indicating a persistence of action far beyond that which we should expect with such doses.

Table 2.-Persistence of Digitoxin action in Cats

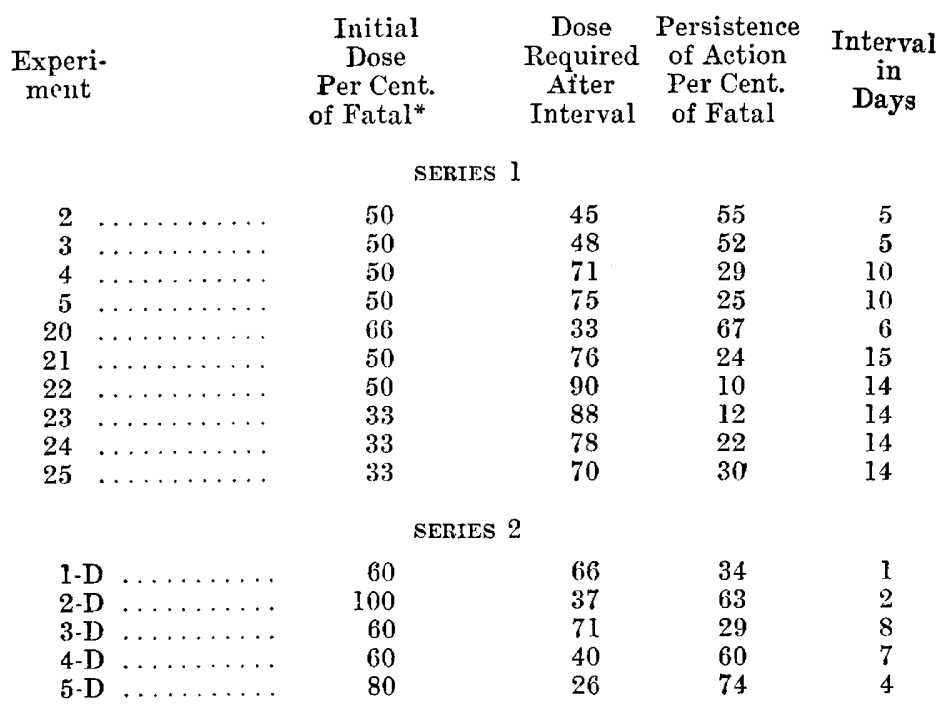

* The fatal dose of the specimen of digitoxin used in the first series was 0.3 mg. per kg. of body-weight; that of the specimen used in the second series was $0.5 \mathrm{mg}$. per $\mathrm{kg}$.

The initial dose in the second series of experiments is reckoned at 100 per cent. of the average fatal, but, as previously stated, six of the twelve animals intended for this series died, and those which survived were slightly tolerant; hence the persistence shown is less than we should expect with such doses. After deducting the 15 per cent. excess of the usual fatal dose, taken by animal No. 1, we have an average of 36 per cent. of the fatal dose persisting after an average interval of sixteen days. (Line 1 of Diagram 1.) 
There are only four experiments in the third series which should be included in the results because the intervals in the others were too long. For the same reason only six of the experiments in the fourth series should be included in the calculations. These six give an average persistence of action equal to 31 per cent. of the fatal dose after an average interval of eleven days. (Line 2, Diagram 1.)

Taking all of the experiments in Series 2, and all of the remaining in the table in which the interval is less than four weeks, we have a total of twenty-five experiments with an arerage persistence of action equal to 23 per cent. of the fatal with an interval of eleven days following an average initial dose equal to 67 per cent. of the fatal, (line 3, Diagram 1). The nearly parallel lines of this diagram afford strong evidence that the results are approximately correct.

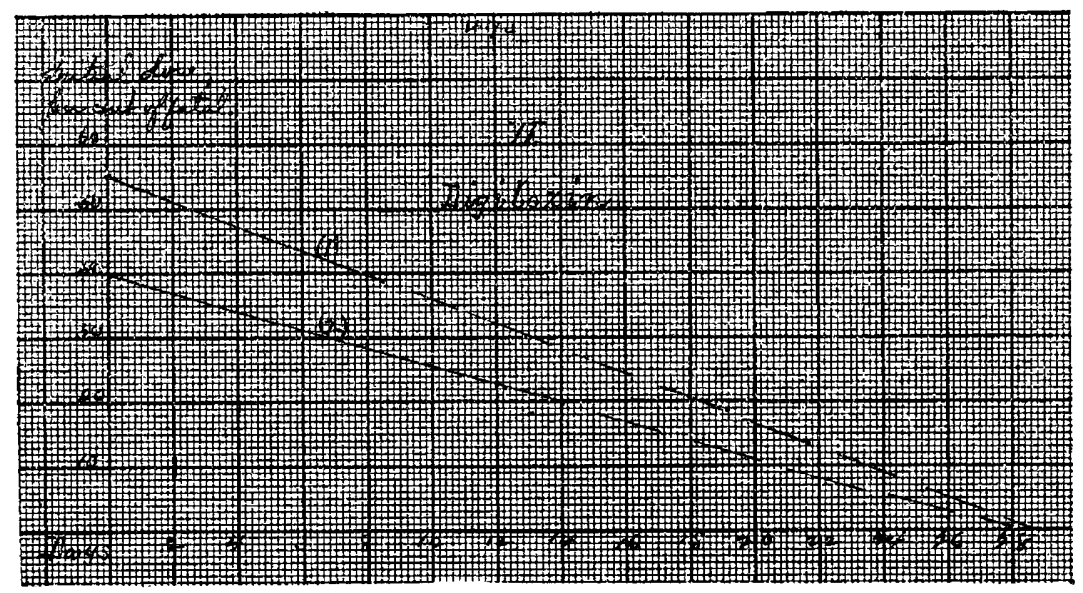

Diagram 2.-Showing persistence of action of digitoxin. Upper line based on all the experiments in Table 2; lower line based on five experiments with nearly equal dosage and intervals before the final test.

It is not necessary to call attention to every experiment in which the results are not in strict agreement with the general average, but it will be seen at once that four of the animals-2, 3, 20 and 25 of the first series in Table 2 - were distinctly susceptible, since they required less in the initial and final doses combined than the average fatal dose. These four experiments prolong the average persistence of the series unduly, but, on the other hand, the first and second animals in Serjes 2 , were just as certainly tolerant; hence the average persistence of this series would be shorter than it should be, and it is believed that the line (1) in Diagram 2 representing the entire number of experiments, sixteen, is very nearly a correct representation of the persistence of action of digitoxin in the cat. 


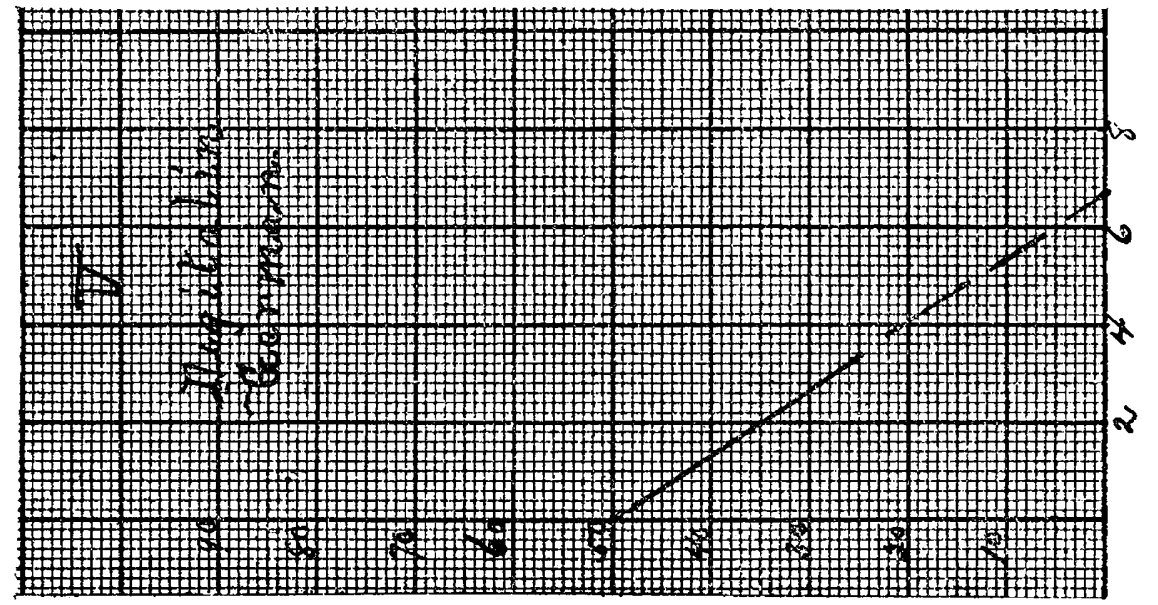

$\equiv \quad . x$

5

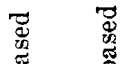

(2)

(2)

$\Xi$

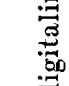

(1)

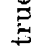

范

落

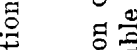

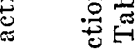

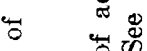

\begin{tabular}{lll}
\hline &
\end{tabular}

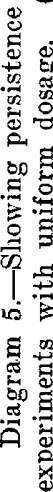

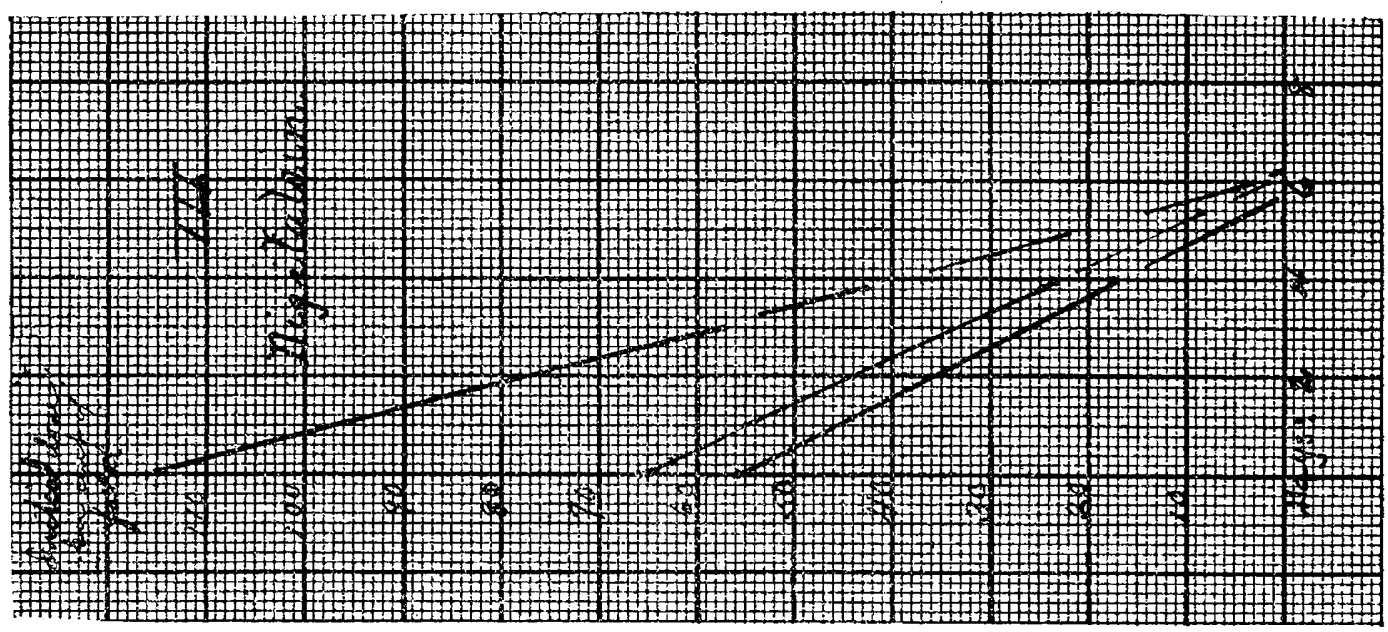

Diagram 3.- Showing the persistence of action of digitalein. Upper line based on all experiments in Table 3; middle line based on experiments in Series 2 of Table 3; lower line based on four experiments with nearly equal doses and a uniform interval of time before final test. 
Line 2 in the diagram, representing the five animals with nearly uniform initial dosage and practically uniform intervals of fourteen days (one fifteen days), is nearly parallel with line 1 . None of the fifteen animals failed to show the persistence of action.

\section{Table 3.-Persistence of Digitalein Action in Cats}

$\begin{array}{ccccc}\text { Experi- } & \text { Initial } & \text { Dose } & \text { Persistence } & \text { Interval } \\ \text { ment } & \text { Dose } & \text { Required } & \text { of Action } & \begin{array}{c}\text { in } \\ \text { Per Cent. }\end{array} \\ \text { of Fatal } & \text { After } & \text { Per Cent. } & \text { Days }\end{array}$

SERTES 1

\begin{tabular}{|c|c|c|c|c|}
\hline 26 & $\ldots \ldots \ldots \ldots$ & 60 & 102 & -2 \\
\hline 27 & $\ldots \ldots \ldots \ldots$ & 30 & 76 & 24 \\
\hline 28 & $\ldots \ldots \ldots \ldots$ & 50 & 84 & 16 \\
\hline 29 & $\ldots \ldots \ldots \ldots$ & 45 & 96 & 4 \\
\hline 30 & $\ldots \ldots \ldots{ }$ & 45 & 90 & 10 \\
\hline 31 & $\ldots \ldots \ldots \ldots$ & 60 & 71 & 29 \\
\hline 32 & $\ldots \ldots \ldots \ldots$ & 60 & 83 & 17 \\
\hline $32 \mathrm{a}$ & $\ldots \ldots \ldots \ldots$ & 60 & 67 & 33 \\
\hline $32 \mathrm{~b}$ & $\ldots \ldots \ldots \ldots$ & 60 & 86 & 14 \\
\hline $32 \mathrm{c}$ & $\ldots \ldots \ldots \ldots$ & 60 & 86 & 14 \\
\hline $32 \mathrm{~d}$ & $\ldots \ldots \ldots \ldots$ & 60 & 69 & 31 \\
\hline $32 \mathrm{e}$ & $\ldots \ldots \ldots \ldots$ & 60 & 110 & -10 \\
\hline $32 \mathrm{f}$ & $\ldots \ldots \ldots \ldots$ & 60 & 86 & 14 \\
\hline
\end{tabular}

SERIES 2

$\begin{array}{llllll}32 \mathrm{~g} & \ldots \ldots \ldots \ldots & 45 \times 3^{*} & 37 & 63 & 3 \\ 32 \mathrm{~h} & \ldots \ldots \ldots \ldots & 45 \times 3^{*} & 29 & 71 & 3 \\ 32 \mathrm{i} & \ldots \ldots \ldots \ldots & 45 \times 3^{*} & 56 & 44 & 3\end{array}$

*Three initial doses of 45 per cent. of the fatal were given on three successive days in these three experiments, the final test being made on the fourth day.

Table 4.-Persistence of Action of Digitaind (True) in Cats

\begin{tabular}{|c|c|c|c|c|c|}
\hline $\begin{array}{c}\text { Experi } \\
\text { ment }\end{array}$ & & $\begin{array}{l}\text { Initial } \\
\text { Dose } \\
\text { Per Cent. } \\
\text { of Fatal }\end{array}$ & $\begin{array}{c}\text { Dose } \\
\text { Required } \\
\text { After } \\
\text { Interval }\end{array}$ & $\begin{array}{c}\text { Persistence } \\
\text { of Action } \\
\text { Per Cent. } \\
\text { of Fatal }\end{array}$ & $\begin{array}{c}\text { Interval } \\
\text { in } \\
\text { Days }\end{array}$ \\
\hline 17 & $\cdots$ & $50 \times 2$ & 55 & 45 & 2 \\
\hline 18 & $\ldots \ldots \ldots \ldots$ & $50 \times 2$ & 131 & -31 & 2 \\
\hline 20 & $\ldots \ldots \ldots \ldots$ & 66 & 88 & 12 & 2 \\
\hline 21 & $\ldots \ldots \ldots \ldots$ & 66 & 82 & 18 & 2 \\
\hline 22 & $\ldots \ldots \ldots \ldots$ & $50 \times 2+33$ & 65 & 35 & 3 \\
\hline 23 & $\ldots \ldots \ldots \ldots$ & $33 \times 3$ & 74 & 26 & 3 \\
\hline
\end{tabular}

The persistence of digitalein action is shown to be brief in the experiments tabulated here, hence those experiments in which the interval was fourteen days should not be included in the calculation; it will be observed, however, that the sum of the combined doses required by these two animals divided by two gives 98 per cent. of the average fatal, as we should expect after the action of the initial dose had ceased. 
Diagram 3 shows a close parallelism between the three lines, (1) based on the averages of all of the experiments in both series; (2) that based on the three experiments in the second series; and (3) that based on the four experiments in which nearly equal doses were given, and a uniform period of four days was allowed to elapse before the final tests were made.

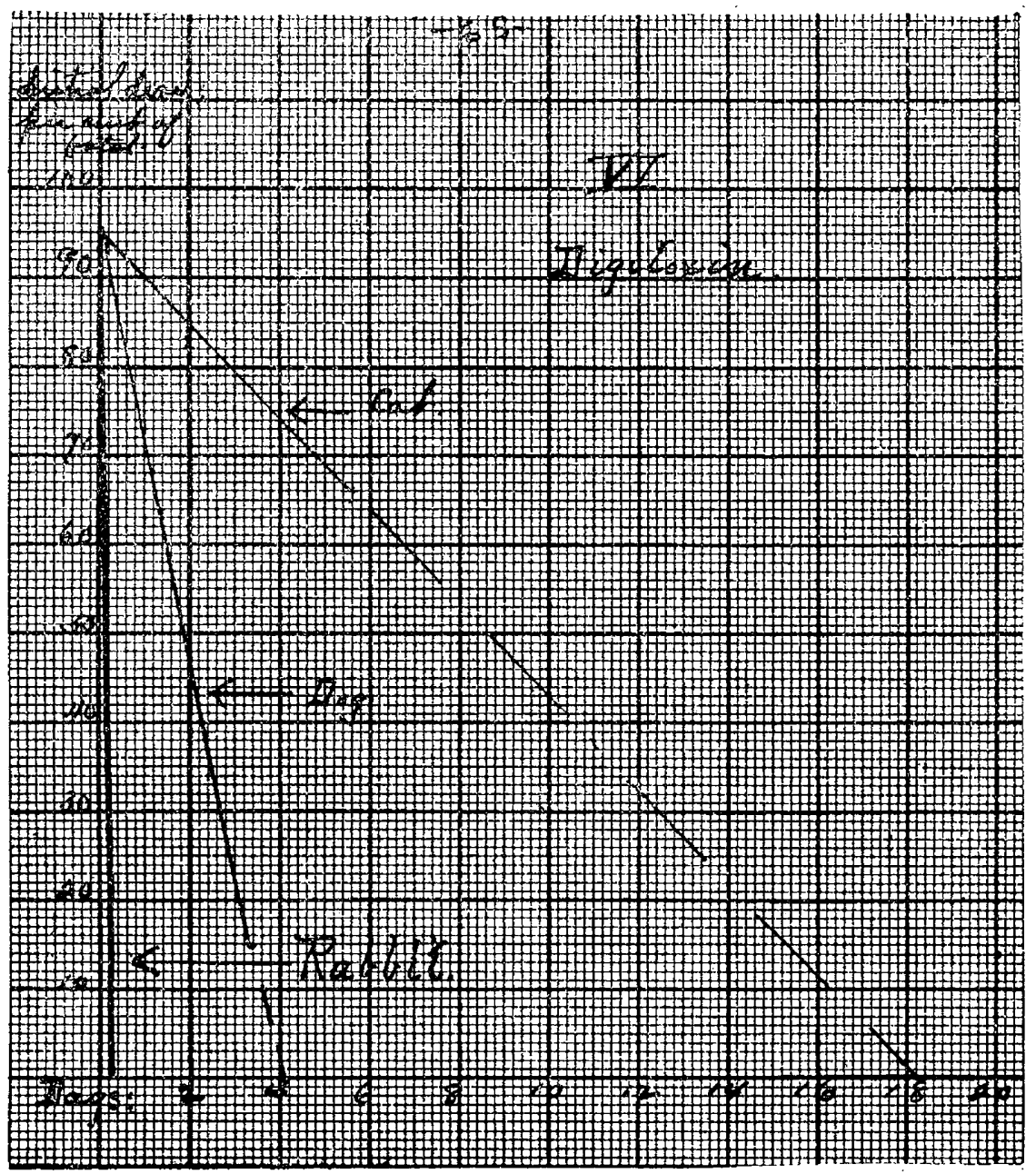

Diagram 6.-Showing persistence of action of digitoxin, on the cat (upper line), dog (middle line), and rabbit (nearly perpendicular line).

The diagrams representing the results obtained with German digitalin, true digitalin and digitalein are placed together for convenience of comparison. 
Two initial doses of 50 per cent. of the fatal were given on successive days in Experiments 17 and 18, and three initial doses were given on successive days in Experiments 22 and 23, and in all four experiments the final test was made on the day following the last initial dose.

In Experiments 20 and 21 a single initial dose was given and the final test was made after an interval of two days.

The averages of the six experiments in Table 4 are as follows:

Initial dose 94 per cent. of the fatal; dose required after an average interval of two and one thisd days, equal to 82 per cent. of fatal, leaving a persistence of action equal to 18 per cent. of the average fatal.

The averages are represented in Diagram 4. Talee 5.-Persistence of Action Crystalline Odabatix ayd Stropiantirus

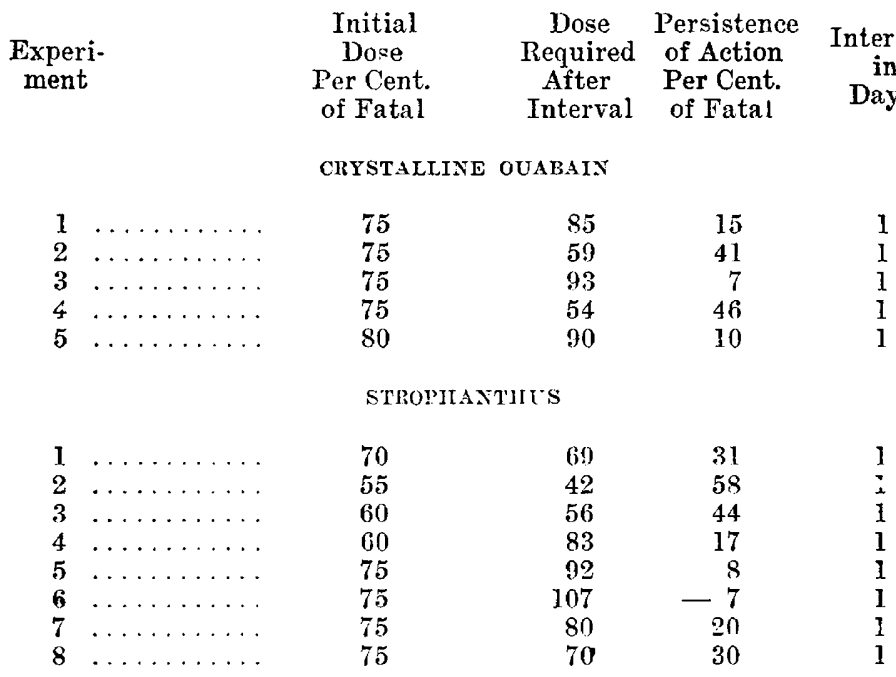

Fraenkel ${ }^{4}$ found that digitalin possessed very little of the so-called cumulative action, and this agrees very well with my own results, which are shown in a striking way in the diagram.

Ouabain, strophanthin (which is methyl-ouabain) and strophanthus are generally supposed to exhibit the cumulative action to a slight degree only, or not at all.

All but one of the animals in the thirteen experiments recorded in Table 5 show some persistence of action after an interval of one day. Ore of the animals (No. 2 of the second series) was evidently unusually susceptible, and one (No. 6 of this series) is just as obviously tolerant, but the averages afforded by the experiments show that these drugs belong in the class with true digitalin, so far as the persistence of action is concerned. 
'Table 6.-Persistexce of Action of Variods Digitalixs ix Cats

$\begin{array}{ccccc}\text { Experi- } & \text { Initial } & \text { Dose } & \text { Persistence } & \text { Interval } \\ \text { ment } & \text { of Fatal } & \text { Interval } & \text { of Fatal } & \text { in } \\ & \text { l'er Cent. } & \text { After } & \text { Per Cent. } & \text { Days }\end{array}$

\section{CONFALIARIA}

$\begin{array}{lllrrr}40 & \ldots \ldots \ldots \ldots \ldots & 60 & 99 & 1 & 3 \\ 41 & \ldots \ldots \ldots \ldots \ldots & 75 & 72 & 28 & 1 \\ 42 & \ldots \ldots \ldots \ldots \ldots & 75 & 92 & 8 & 1 \\ 43 & \ldots \ldots \ldots \ldots \ldots & 70 & 57 & 43 & 1 \\ 44 & \ldots \ldots \ldots \ldots \ldots & 75 & 94 & 6 & 1 \\ & & & \end{array}$

$\begin{array}{llllrl}14 & \ldots \ldots \ldots \ldots & \mathbf{7 5} & 94 & 6 & 1 \\ 15 & \ldots \ldots \ldots \ldots & \mathbf{7 5} & \mathbf{6 0} & 40 & 1 \\ 16 & \ldots \ldots \ldots \ldots & \mathbf{7 5} & 95 & 6 & 4 \\ 17 & \ldots \ldots \ldots \ldots & 50 & 86 & 14 & 1 \\ 18 & \ldots \ldots \ldots \ldots & 40 & 98 & 2 & 1 \\ 19 & \ldots \ldots \ldots \ldots & 50 \times 2 & 75 & 25 & 3\end{array}$

GERMAN DIGITAIIX

$\begin{array}{llrrrr}10 & \ldots \ldots \ldots \ldots & 50 & 37 & 63 & 3 \\ 17 & \ldots \ldots \ldots \ldots & 50 & 100 & 0 & 3 \\ 18 & \ldots \ldots \ldots \ldots & 50 & 57 & 53 & 1 \\ 19 & \ldots \ldots \ldots \ldots & 50 & 86 & 14 & 2 \\ 20 & \ldots \ldots \ldots \ldots & 50 & 114 & -14 & 3 \\ 22 & \ldots \ldots \ldots \ldots & 50 & 66 & 34 & 9\end{array}$

SQUILL

$\begin{array}{llllll}13 & \ldots \ldots \ldots \ldots & \mathbf{7 0} & \mathbf{8 0} & \mathbf{2 0} & \mathbf{1} \\ \mathbf{1 4} & \ldots \ldots \ldots \ldots & \mathbf{5 0 \times 3} & \mathbf{5 4} & \mathbf{4 6} & \mathbf{3} \\ \mathbf{1 5} & \ldots \ldots \ldots \ldots & \mathbf{5 0 \times 3} & \mathbf{3 0} & \mathbf{7 0} & \mathbf{3} \\ 16 & \ldots \ldots \ldots \ldots & \mathbf{5 0 \times 3} & 42 & \mathbf{5 8} & \mathbf{3} \\ \mathbf{1 7} & \ldots \ldots \ldots \ldots & \mathbf{8 0} & \mathbf{5 7} & 43 & \mathbf{2} \\ 18 & \ldots \ldots \ldots \ldots & \mathbf{8 0} & \mathbf{7 1} & \mathbf{2 9} & \mathbf{2}\end{array}$

BLACK HELLEBORE

$-\cdot$

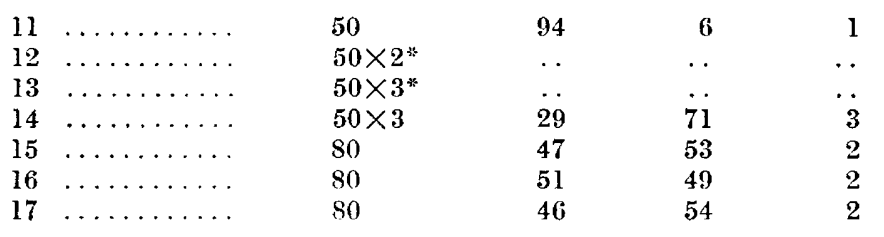

HELLEBOREIN

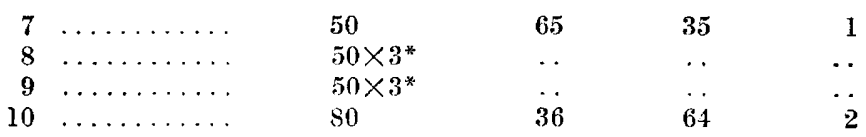

*Fatal. 


$\begin{array}{ccccc}\text { Experi- } & \text { Initial } & \text { Dose } & \text { Persistence } & \text { Interval } \\ \text { of Fatal } & \text { Interval } & \text { of Fatal } & \text { in } \\ & \text { Per Cent. } & \text { After } & \text { Per Cent. } & \text { Days } \\ & \text { Dose } & \text { Required } & \text { of Action } & \text { Days }\end{array}$

CONVAILLAMARIN

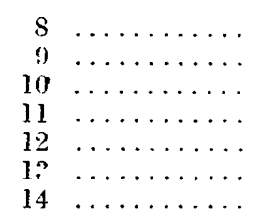

44
70
70
$45+50$
$45+50+50$
80
80

$\begin{array}{lll}64 & 36 & 1 \\ 68 & 32 & 2 \\ 74 & 26 & 2 \\ 73 & 27 & 2 \\ 39 & 61 & 3 \\ 89 & 11 & 2 \\ 73 & 27 & 2\end{array}$

SCILJ.ITONIN
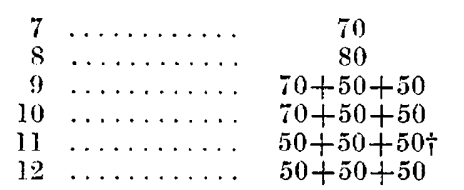

$7_{0}$
60
60
35
29

$\begin{array}{ll}30 & 3 \\ 40 & 3 \\ 40 & 7 \\ 65 & 7 \\ 78 & 3\end{array}$

EUONYMUS

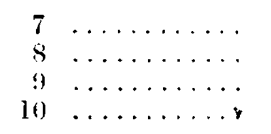

$\begin{array}{ll}50 & 10 \\ 50 & \end{array}$

102
87
54

$50 \times 2$

44

$\begin{array}{rr}2 & 1 \\ 13 & 1 \\ 46 & 2 \\ 56 & 2\end{array}$

ADONIDIN

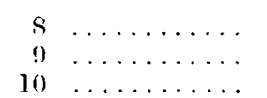

$$
\begin{array}{r}
5 s+581 \\
58+58+58 \\
80+60
\end{array}
$$

42
27

$\overline{5} 8$

73

$\ddot{3}$

4

†ि Suldenly iatal.

Thie experiments furnish the following averages:

Crystalline ouabain, initial dose, 76 per cent. of fatal; persistence of action after an interval of one day equal to 24 per cent. of the fatal: strophanthus, initial dose, 68 per cent. of fatal; persistence of action after an interval of one day equal to 25 per cent. of the fatal.

In several of the experiments in Table 6 the animals received more than one initial dose; in such cases these were given on successive days. except in the case of scillitoxin, in which the initial doses were given at intervals of two days. In all cases the interval before the final test is reckoned from the date of the first initial dose.

German digitalin is said to consist of digitonin to a very large extent. and the action of digitonin on the heart is not quite like that of true digitalin, so that it is not surprising that the results obtained with this preparation are not very satisfactory. The similarity of action to that of cligitalein is to be noted.

Digitalis also contains digitonin, but the amount present in the leaf is said to be small, and it should be remembered that the cardiac action 
of digitonin is not obtained after the oral administration of digitalis or the other digitalins. The final test was made with the same drug which was used for the initial dose in every experiment recorded in Table 6 , but we liad found that all of these digitalis bodies are synergists of ouabain.

The digitoxin was administered intramuscularly in Experiments 1 to 9 inclusive, and intravenously in the others.

Tabie 7.- l'persistence of Digitoxin action in Dogs

$\begin{array}{ccccc}\begin{array}{c}\text { Experi- } \\ \text { ment }\end{array} & \begin{array}{c}\text { Initial } \\ \text { Dose } \\ \text { Per Cent. } \\ \text { of Fatal }\end{array} & \begin{array}{c}\text { Dose } \\ \text { Required } \\ \text { After } \\ \text { Interval }\end{array} & \begin{array}{c}\text { Persistence } \\ \text { of Action } \\ \text { Per Cent. } \\ \text { of Fatal }\end{array} & \begin{array}{c}\text { Interval } \\ \text { in } \\ \text { Days }\end{array} \\ 1 & 95 & 60 & 40 & 3 \\ 2 & 60 & 100 & 00 & 11 \\ 4 & 95 & 100 & 00 & 2 \\ 5 & 90 & 75 & 25 & 9 \\ 7 & 95 & 100 & 00 & 5 \\ 9 & 95 & 100 & 00 & 9 \\ 10 & 95 & 77 & 23 & 1 \\ 11 & 95 & 67 & 33 & 1 \\ 12 & 80 & 100 & 00 & 3 \\ 13 & 95 & 100 & 00 & 3\end{array}$

Table 8.-Digitalis in Repeated Doses to Rabbits Ixtrayexously

(Doses in milligrams per kilogram of body-weight)

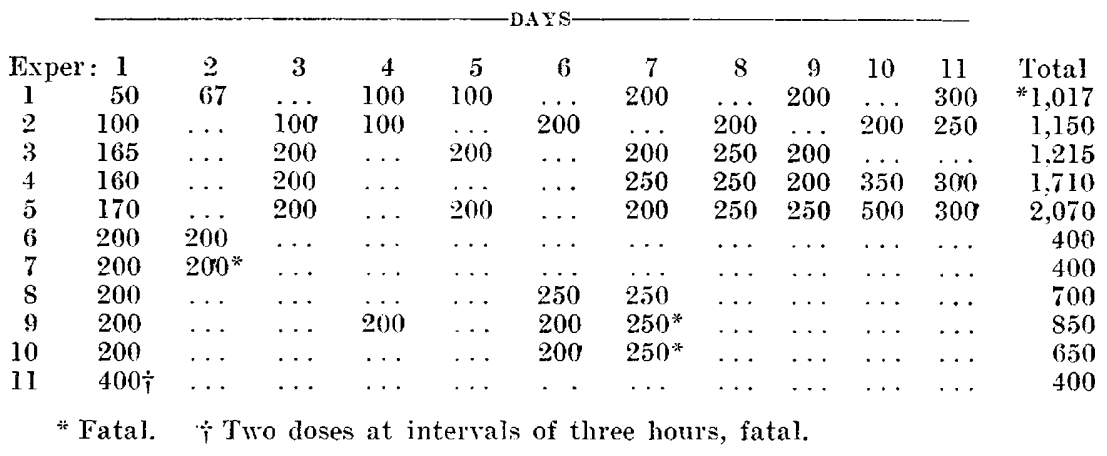

It is evident that dogs do not usually show persistence of digitoxin action for long periods, and of the eight experiments in which the duration of the interval was more than a day, only two, (1 and 5,) show any persistence of action. That the action did actually persist in these two cases is rendered more probable by the fact that the first of these animals, which shows persistence of action amounting to 40 per cent. of the fatal after three days, was greatly depressed for two days following the first dose, and the other animal, which shows persistence of action cqual to 25 
per cent. of the fatal, had lost $1.5 \mathrm{~kg}$. of body-weight during the interval. The weight at the time of the first injection was $12.5 \mathrm{~kg}$, and at the time of the final test the weight was $11 \mathrm{~kg}$.

Here again the attention is arrested by the question whether individual differences in tolerance and susceptibility stand in any sort of relation to differences in the individual capacity for climination, as snggested in the discussion of 'Table 1.

In the fourth and fifth experiments the animals received two doses each on the tenth day. Two hundred and fifty $\mathrm{mg}$. of digitalis per $\mathrm{kg}$. of body-weight appears to be the average fatal intravenous dose for the rabbit, but two rabbits survived doses of $300 \mathrm{mg}$. per $\mathrm{kg}$. each, and one of these, No. 5, had had two doses of $250 \mathrm{mg}$. per $\mathrm{kg}$. each on the previous day.

Table 9.-Efeect on Digitoxix in Repeated Doses to Rabeits by Vern

(Doses are giveil in milligrams per kilogran of weight)

\begin{tabular}{|c|c|c|c|c|c|c|c|c|c|}
\hline Exper. & 1 & $\underline{2}$ & 3 & 4 & $\tilde{z}$ & 6 & 7 & 8 & Total \\
\hline 1 & 0.75 & & 0.5 & 0.75 & $\ldots$ & & & $\ldots$ & 2.0 \\
\hline 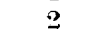 & 0.5 & 0.5 & 0.5 & 0.5 & $\ldots$ & 0.5 & 0.75 & $\ldots$ & 3.25 \\
\hline $\overrightarrow{3}$ & 0.5 & $\ldots$ & $0 . \overline{3}$ & 0.5 & $\ldots$ & $0 . \tilde{5}$ & 0.75 & $\ldots$ & $* 2.75$ \\
\hline 4 & 0.75 & $\ldots$ & $1 . \overline{3}$ & 1.5 & $\ldots$ & & & $\ldots$ & ${ }^{*} 3.75$ \\
\hline$\tilde{\sigma}$ & 0.5 & & 0.75 & 0.75 & & 0.75 & 0.75 & $\ldots$ & 3.5 \\
\hline 6 & 0.75 & 0.75 & 0.75 & ... & $0 . \overline{5}$ & 0.75 & & & 3.75 \\
\hline 7 & 0.5 & 0.75 & 0.75 & $\ldots$ & 0.75 & 0.7 .5 & 0.75 & 0.65 & +7.0 \\
\hline
\end{tabular}

"Fatal $†$ 1.0 milligram on tenth day and $1.0 \mathrm{mg}$. on twelfth day.

The eleven rabbits weighed $18.44 \mathrm{~kg}$, they received a total of 19,000 mg. of digitalis during a total of seventy days of experimentation, or an average of less than a week for each animal, but even this stupendous amount does not represent the limits of dosage for this animal; but its capacity for eliminating the digitalins was not suspected at the time the experiments were conducted.

In this connection it must be remembered that the amounts administered to these rabbits correspond to very much larger amounts administered by the stomach, or subcutaneously.

The fourth animal of this series died of respiratory failure. 'The seven rabbits received an average total of more than $3.5 \mathrm{mg}$. of digitoxin per $\mathrm{kg}$. during the entire period.

Impressive as the figures for this and the preceding table are, they lose much of their significance in view of the results recorded in Table 10, in which it is shown that the rabbit eliminates digitoxin with surprising rapidity. 
The following is the protocol of an experiment which shows that the rabbit exhibits no persistence of action of digitoxin after an interval of a few hours following the intravenous administration of a nearly fatal dose.

May 29, 1912: Rabbit, weight, $1.7 \mathrm{~kg}$.

$8: 41$ a. $\mathrm{m}$. $1.0 \mathrm{mg}$. digitoxin per $\mathrm{kg}$. by vein; some depression.

9:4I a. m. Animal sitting up.

$12: 56$ p. m. $1.0 \mathrm{mg}$. digitoxin per $\mathrm{kg}$. as before.

1:10 p. m. Effects about the same as after previous dose.

$1: 56$ p. m. Appears to be nearly normal.

2:56 p. m. Ouabain, slow and continuous injection by vein.

$3: 34 \mathrm{p}$. $\mathrm{m}$. Death after injection of $0.19 \mathrm{mg}$. ouabain per $\mathrm{kg}$., or the full fatal dose of ouabain.

Table 10.-Persistence of Action of Digitoxix in the Rabbit

(Doses in mg. per $\mathrm{kg}$. of body-weight)

Initial Dose
of Digitoxin
$4.0 \quad$ (subcut.)
0.75 (vein)
0.75 (vein)
$2.0 \quad$ (vein)

Dose Required
After Interval
0.206 ouabain
0.245 ouabain
0.212 ouabain
0.19 ouabain

$\begin{array}{cc}\text { Interval in } & \text { Persistence } \\ \text { Hours } & \text { of Action } \\ 26 & 00 \\ 4.5 & 00 \\ 4.5 & 00 \\ * & 00\end{array}$

* See proctocol.

I believe that hitherto no one has suspected that the rabbit is capable of eliminating digitalis and digitoxin with the extraordinary rapidity indicated in Tables 8, 9 and 10, and as shown in the protocol of the experiment. Certainly no one has ever before recorded the administration of digitoxin in such amounts and at such short intervals during studies of this nature, for it must be remembered that the subcutaneous and oral administration are in no way comparable to the intravenous injection of this principle, because of the slow and uncertain absorption from the gastro-intestinal tract and from the subcutaneous tissues of the rabbit. (See Experiment 1, Table 10.)

It is hardly necessary, therefore, to call attention to the fact that previous studies of cumulation, so-called, based on the oral or subcutaneous administration of the digitalins to rabbits lose much of their value because it is obvious that absorption is a more important factor in the results so obtained than is the persistence of action which follows the absorption into the blood-stream of the drugs so administered.

It will be understood that the doses given in Table 11 apply only to the specimens of the drugs used by us in these experiments, but crystalline ouabain appears to be of constant composition and activity.

The fluid extracts used were obtained from a reputable firm, but it is probable that they do not represent the full activity of the drugs from which they were prepared. The tincture of digitalis used was prepared in this laboratory, care being taken to insure the complete exhaustion of the drug. 
* table 11.-Fatal Doses of Digitaliss by Vein in Milligrams per KiloGRAMI OF BODY-WEIGHT

CAT

\begin{tabular}{|c|c|}
\hline dabain ${ }^{\circ}$ (crystalline strophanthin, so called) ... & 0.1 \\
\hline Digitoxin (specimen used in Series 1 , Table 2)... & 0.3 \\
\hline Digitoxin (specimen used in Series 2 , Table 2$) \ldots \ldots \ldots \ldots \ldots \ldots$ & 0.5 \\
\hline$\ldots \ldots \ldots \ldots \ldots \ldots \ldots$ & 0.4 \\
\hline Digitalin (true) $\ldots$ & 1.5 \\
\hline$\ldots \ldots \ldots \ldots$ & 1.7 \\
\hline amarin & 1.7 \\
\hline$\ldots$ & 3.5 \\
\hline alin, German & 3.6 \\
\hline Ado & 4.35 \\
\hline llaria (fluid extract used). & 50.0 \\
\hline um (fluid extract used). & 70.0 \\
\hline are prepared by ourselves) & .00 \\
\hline (fluid extract) $\ldots \ldots \ldots$ & 100.00 \\
\hline ngmi & 475.0 \\
\hline did extra & \\
\hline
\end{tabular}

DOG

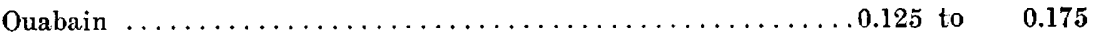

Digitoxin (specimen used in Series 1, Table 2)..............

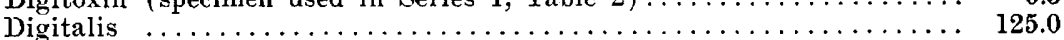

RABBIT *

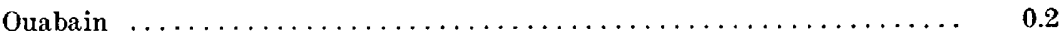

Digitoxin (specimen used in Series 1 , Table 2$) \ldots \ldots \ldots \ldots \ldots .75$ to 1.0

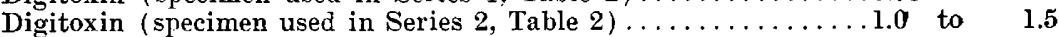

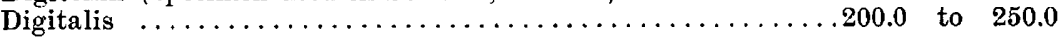

* The doses given are for rabbits weighing about 1,800 gm. or less; fully grown rabbits appear to be slightly more susceptible than this to the digitalins.

Reference to the table suggests some curious relationships between several of the digitalins; for example, digitoxin and scillitoxin are about equal in activity and their persistence of action is not widely different; true digitalin, helleborein and convallamarin are almost exactly alike in activity, and none of these three shows a markedly persistent action. German digitalin and digitalein are about equal in activity, and we know that both of these partake of the nature of true digitalin on the one hand, and of digitonin on the other. ${ }^{10}$

Too much stress should not be placed on similarities in activity of the digitalins, however, since none of these bodies except ouabain is found in commerce in a pure form. Ouabain appears to have only traces of impurities present.

\section{ANALYSIS OF CERTAIN RESULTS OF FRAENKEL'S}

Reference has been made to the fact that Fraenkel's conclusions based on results obtained when using digitalins on the cat are irreconcilable with mine. It is necessary, therefore, to discuss some of his experiments

10. Schmiedeberg: Arch. f. exper. Path. u. Pharm., 1875, iii, 16. 
which, interpreted correctly, actually confirm my own results in all essentials, I believe.

Fraenkel ${ }^{4}$ fixed the fatal dose of Merch's crystalline digitoxin for the cat by subcutaneous injection at $0.08 \mathrm{mg}$. per kg. of body-weight and then he administered specified fractional parts of this dose daily, observing the onset and severity of the gastro-intestinal symptoms, the effects on the heart and pulse-rate and the number of such doses that the animal would survive, comparing the effects of digitoxin with those of the other digitalins in common use, including digitalin and strophanthin.

\section{Table 12.-Effect of Digitoxin on Cats}

(Taken from article by Fraenliel ${ }^{4}$ )

\begin{tabular}{|c|c|c|c|c|c|}
\hline Experi- & Digitoxin & After & After How & After How & Remarks \\
\hline ment: & Given & How & Many & Many & $\cdots$ \\
\hline 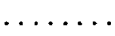 & Per Kg. & Many & Doses & Doses & $\cdots$ \\
\hline & $\cdots$ & Days & Vomit- & Sick? & . \\
\hline & & Slowing? & ing? & & \\
\hline 40 & $22 \times 0.02$ & 5 & Not seen. & Not seen. & Remained sound. \\
\hline 9 & $9 \times 0.03$ & 2 & 3 & 9 & $\begin{array}{l}\text { Stopped; Animal ver } \\
\text { sick. }\end{array}$ \\
\hline 20 & $2 \times 0.04$ & 2 & Not seen. & Not seen. & Remained sound. \\
\hline 44 & $16 \times 0.04$ & 4 & 6 & 6 & Death after 16 doses. \\
\hline 11 & $5 \times 0.041$ & 3 & 5 & $\overline{5}$ & $\begin{array}{l}\text { Stopped after } 5 \text { doses; } \\
\text { very sick. }\end{array}$ \\
\hline 8 & $7 \times 0.05$ & $3-4$ & $3 \cdot 4$ & 4 & Death after 7 doses. \\
\hline 10 & $7 \times 0.087$ & 1 & 2 & 3 & Death after 7 doses. \\
\hline
\end{tabular}

It will be seen by reference to Table 12, which is taken from Fraenkel's article, that several of his cats survived a total of much more than the amount which Fraenkel gives as the single fatal dose; thus, one of his animals is stated to have received sixteen daily doses, each of which was 50 per cent. of the fatal, or a total amount equal to eight times the single fatal dose within a period of fifteen days; another survived three times the fatal single dose, administered in five days; while two required to cause death amounts equal to four and seven, times the fatal dose, respectively, within a period of a week.

If these conclusions were correct it would show that the action of digitoxin is not very persistent when used in that way, but while Fraenkel does not state specifically the number of experiments which he made to determine the toxicity of digitoxin for the cat, he gives the protocol of only one experiment and in that the animal died on the tenth day after the injection.

No less than five observers working independently in this laboratory at different times have been unable to confirm Fraenkel's determination of the fatal dose of digitoxin for the cat.

Bailey, Brody, Eggleston, Mr. M. I. Smith (one of my students), and I have found that the fatal dose of different samples of Merck's crystalline digitoxin is much larger than that given by Fraenkel. 
Bailey found that doses of $0.1 \mathrm{mg}$., and $0.2 \mathrm{mg}$., per $\mathrm{kg}$. of bodyweight injected subcutaneously, produced very little effect on the pulserate of the cat, and, in fact, little or no perceptible effect of any sort was produced by these doses administered to two animals.

Hatcher and Brody, ${ }^{9}$ Eggleston, and later I, while repeating the work, have found that the fatal intravenous dose of several different samples of Merck's crystalline digitoxin for the cat is approximately $0.3 \mathrm{mg}$. to $0.35 \mathrm{mg}$. per $\mathrm{kg}$. of body-weight, and I have found the fatal dose for the cat by subcutaneous injection to be somewhat larger than that by vein, as one might expect. I have quite recently found a specimen of Merck's digitoxin obtained from another firm, and not bearing Merck's label, to have only about 60 per cent. of the activity of the specimens previously examined. (This is the weaker specimen mentioned in Table 11.)

If we accept $0.4 \mathrm{mg}$. of digitoxin per $\mathrm{kg}$. of body-weight as the average fatal dose for the cat by subcutaneous injection, it will be seen that Fraenkel's results, so far from being irreconcilable with my own, afford strong corroborative evidence of the persistence of action in the cat.

If the fatal dose of digitoxin used by Fraenkel was really $0.4 \mathrm{mg}$. per $\mathrm{kg}$. when administered subcutaneously, his animals received only a Iittle more than the single fatal dose within a period of a week, and instead of receiving totals of three, four, seven and eight, times the single fatal dose, respectively, they received totals of three-fifths (this animal survived), one, one and a half, and one and three-fifths times the single fatal dose, from which the last three died.

One might argue that the specimen of Merck's crystalline digitoxin used by Fraenkel was far more active than the specimens used in this laboratory, and I am well aware that it is commonly stated that the activity of different specimens of all of the digitalis principles varies widely, but while the activity of a given principle made by different manufacturers may show great rariations, and the product made at different times by the same manufacturer may vary somewhat, the results obtained by numerous observers indicate no rery great variation in the activity of Merck's crystalline digitoxin.

Among those who have determined the activity of digitoxin and whose results are in fair agreement with those obtained in this laboratory (allowance bcing made for differences due to different methods of testing), are: Lyons and Famulener, ${ }^{11}$ Worth Hale ${ }^{12}$ and Koppe. ${ }^{13}$ On the other hand, I know of no one whose results confirm those of Fraenkel.

11. Lyons and Famulener: Proc. Am. Pharm. Assn., 1902, 1, 424.

12. Hale, Worth: Bull. 74, 1911, Hyg. Lab., U. S. Public Health and MarineHospital Service.

13. Koppe: Arch. f. exper. Path. u. Pharmakol., 1875, iii, 274. 
If the digitoxin used by Fraenkel behaved in the way indicated by him it means that the specimen of Merck's digitoxin employed by him is far more active than any which has been used in experimentation in this country, and furthermore, that its behavior is much more like that of ouabain, so far as persistence of action is concerned, than like that of digitalis.

No other worker either in Europe or America has ever reported such activity for digitoxin on mammals as Fraenkel has reported in this series of experiments, so far as I am aware, and I believe that Fraenkel's results with repeated injections disprove his own statement as to the lethal dose of this drug, if by lethal dose we are to understand the amount which will kill at least half of the animals in a series through the action on the heart.

There is little doubt that when an animal is made ill by the injection of one of the digitalins it is more apt to succumb to more or less accidental conditions during a prolonged confinement than is a normal animal, and I believe it to be wholly erroneous to attribute all the deaths which occur in ten days or more after the administration of a single dose of the digitalins to the cardiac action of the drug.

It might be urged that digitoxin behaves differently after subcutaneous and intravenous injections; I have, therefore, repeated Fraenkel's experiments to the extent of injecting repeated doses of less than 50 per cent. of the fatal dose subcutaneously. In these experiments the cats received: $0.6 \mathrm{mg}$. per $\mathrm{kg}$. of body-weight in four days; $0.75 \mathrm{mg}$. per $\mathrm{kg}$. in five days; and $0.7 \mathrm{mg}$. per $\mathrm{kg}$. in three injections in six days, before death resulted. These results agree very well with those reported by Fraenkel so far as the actual amounts administered are concerned. I am therefore forced to the conclusion that the so-called fatal dose of digitoxin as determined by Fraenkel, can be fatal only under very exceptional conditions, and is of no value whatever in determining the persistence of action of digitoxin.

This misconception of the activity of digitoxin appears to have led Fraenkel into another error. He concluded that the interval of time which must elapse after a digitalis principle enters the circulation before its action on the heart is induced must be proportional to the chemical affinity existing between the drug and the tissue on which it acts, whereas the duration of the action must depend on the stability of the combination of drug and tissue.

The truth of this conclusion, based on theoretical considerations, seems self-evident; nevertheless it was based on a wholly erroneous idea, in that Fraenkel believed that the action of digitoxin on the heart was not exerted for many hours after its introduction into the blood-stream, and he states that even sixty hours may elapse after the administration of 
a toxic dose before this cardiac action is induced. It is obvious that he fell into this error partly because of his erroneous belief that he was administering a highly toxic dose, when, in reality, he was administering only a small part of the fatal dose.

It is perfectly true that digitoxin does not exert its full action immediately after the injection of small amounts into the circulation, but death may result in about five minutes after injection of about twice the ordinary fatal dose of digitoxin directly into the veins of the cat or dog. When a very large dose of digitoxin is injected directly into the veins the action is induced with amazing swiftness, the heart stopping suddenly aimost without warning on its part.

The belief which is well nigh universal, that digitoxin is an extraordinarily toxic substance, is based mainly on the well-known experiment in which Koppe ${ }^{13}$ administered to himself by the mouth three doses of digitoxin amounting altogether to $3.5 \mathrm{mg}$. in a period of five days, $2 \mathrm{mg}$. having been taken four days after the second dose of $1 \mathrm{mg}$.

Since Koppe had previously given a rabbit $4 \mathrm{mg}$. of the digitoxin subcutaneously without causing death, there is little doubt that he was extraordinarily susceptible, or that his illness following the taking of the digitoxin was due to other causes in part.

\section{CONCLUSIONS}

In presenting the results of my experiments $I$ would not intimate a belief that the last word had been spoken concerning the persistence of action of the digitalins or the so-called cumulation of these bodies, but $I$ do believe that my results afford a starting point for investigating the subject anew.

It is obvious that the rabbit is not suited for these studies and that the cat serves the purpose better than the dog. The injection of the digitalins directly into the circulation affords so much greater accuracy of observation than the oral and subcutaneous routes, that the former method alone should be used for these investigations.

Changes in the heart-rate of the cat and the rabbit occur so often independently of the administration of the digitalins that they afford rery little information concerning the persistence of action of these drugs.

The several digitalins vary widely in their toxicity for any given species of animal, and the different species of animals show enormous differences in susceptibility to a given digitalin, but so far as I have been able to determine, as the result of a large number of experiments, the various digitalins maintain their relative positions in order of toxicity, regardless of the animal used for the determination provided that the drug is introduced directly into the circulation; but the absorption of these bodies from the gastro-intestinal tract is so rariable that the effects 
which follow the oral administration afford no clue to the activity which they will exert when they are injected directly into the circulation.

It remains for the clinician to determine whether it will be adrantageous in a given condition to utilize the prolonged actions of digitalis and digitoxin or the briefer actions of strophanthus and digitalin, but it seems more than probable that the more persistent action will be found preferable in certain chronic cardiac conditions, whereas the less lasting digitalin action probably will be preferred in certain conditions such as acute cardiac dilatation.

It is of the first importance to the clinician to know that the various digitalins are synergistic in their action, and that when one member of the group is used in such a way that its action is elicited promptly (as after intramuscular, or intrarenous injection) during the period when the action of a previously used digitalin persists, the dose of the drug so used must be regulated carefully because inattention to this detail may result disastrously.

\section{SUMMARY}

The production of the phenomena commonly called "cumulation" of the digitalins, depends on the relationships existing among a number of factors, including absorption, elimination and persistence of action, all of which are in need of investigation. The use of the term cumulation tends to perpetuate a misconception.

The actions of the digitalins persist for periods of time which vary widely with the different members of the group, and with the species of animal employed.

The actions of digitoxin and digitalis persist longer than do those of the other digitalins in common use.

The cat shows this persistence of digitalis action much longer than the dog, rabbit or white rat.

The cardiac actions of a single very large intravenous dose of digitalis or digitoxin may persist for a full month in the cat, but for only a few hours in the rabbit.

The actions of the largest sublethal dose of digitalin, ouabain or strophanthus persist for only a day, or. at most, a few days, in the cat.

It remains for the clinician to determine whether the long-lasting action of digitalis or the briefer action of strophanthus is to be preferred in a given condition of cardiac disease, but strophanthus cannot rival digitalis in general use until we learn more of the conditions governing its absorption from the gastro-intestinal tract, and of this we know practically nothing at present.

Careful regulation of the therapeutic dosage of the digitalins is necessary in order to avoid accidents. This is especially necessary when they are used in such a way that the action is elicited promptly during 
the period when the action of a previously used digitalin persists, and in this connection it must be remembered that every digitalin is a synergist of every other member of the group.

All of the digitalins maintain their relative position with regard to activity, so far as we have tested them on different mammals, by intravenous injection, and digitoxin has never been found by any observer to be as active as crystalline ouabain when tested on mammals in this way; hence there is no sufficient reason for the wide-spread belief that digitoxin is enormously toxic for man, as compared with other digitalins.

No fixed ratio of activity can be determined for the digitalins when they are administered orally, because of great differences in the rate of absorption from the gastro-intestinal tract.

The full effects of moderately large doses of digitoxin are not exerted on the heart at once even when they are administered intravenously, but severe symptoms of poisoning may be elicited in a few seconds, and death may occur within two minutes, after the intravenous injection of a very large dose of digitoxin.

The rabbit eliminates certain of the digitalins, at least, with a rapidity hitherto unsuspected, and previous studies of the so-called cumulative actions of these bodies, in which they were administered orally, or subcutaneously to rabbits, lead to wholly erroneous conclusions.

Changes in the pulse-rate amounting to fifty beats per minute occur spontaneously in the cat and the rabbit, and large doses of digitalis often fail to elicit any constant changes in the pulse-rate of these animals; hence such changes as may occur after the administration of the digitalins to these animals afford no trustworthy indication of the persistence of action of the digitalins. (See protocol of experiment, p. 273.)

Further studies of the digitalins are in progress in this laboratory, among the problems under investigation being those of absorption from the gastro-intestinal tract; the rate at which the digitalins leave the bloodstream; their elimination from the organism; their storage in the tissues, and their persistence of action.

I wish to acknowledge my indebtedness to Mr. M. I. Smith, one of my students, for assistance in carrying out many of the experiments in this research.

414 East Twenty-Sixth Street. 